\title{
Communication Research Results through Publication
}

\author{
Asnawati Matondang, Syahlan and Saiful Anwar Matondang \\ Universitas Islam Sumatera Utara, J1. Sisingamangaraja, Teladan-Medan \\ Corresponding author: saiful.matondang@ fkip.uisu.ac.id
}

\begin{abstract}
.
Communication through publication plays an important role in higher education. The purpose of this study was to determine the increase in the ability of scientific publications of lecturers through training activities and mentoring to lecturers in writing scientific papers. There are two achievements in this training, namely that the lecturer has the skills to write scientific articles and knowledge on how to check the originality of his scientific work (using the plagiarism checker application), which is included in the original category is less than $20 \%$ detected plagiarism. This research is a qualitative descriptive study. This activity was carried out at the Deli Husada Health Institute, Indonesia. The target audience in this activity is the permanent lecturers of the foundation who have served at least one year and have sufficient ability in the ICT field. The result is that this activity shows satisfactory success when compared to the expected performance plan that is $60 \%$ of participants' activities. The conclusion is that the assistance activities in writing scientific papers of lecturers can significantly improve the ability of lecturers to produce scientific work that can be published.
\end{abstract}

Keywords: communication; publications; lecturers

\section{INTRODUCTION}

The functional position of a lecturer is an acknowledgment of a lecturer's assignment which consists of three elements (tridharma), namely education and teaching, research, and community service. Research is starting to become phenomenal in Indonesia, when international scientific publications originating from Indonesia are in the spotlight, where the ratio is very small when compared to other ASEAN countries (Nasution, 2016). Research results from Indonesian researchers or lecturers have been rarely published. Although researchers / lecturers admit that research requires sharing and transfer.

Scientific publication is evidence that research has been carried out and disseminated to become a reference material among experts who have the same field of expertise. Sometimes a research result is first conveyed in scientific activities in the form of seminars or symposia to be discussed. The research results in the seminar will usually receive improvements so that they meet the eligibility requirements for publication.

There are three recognized publications for scientific papers, namely monograph and reference books, journals and proceedings, and popular newspapers and magazines (Ministry of Education and Culture, 2014). The most popular form of publication of scientific papers today is in the form of scientific journals (national and international). At the present time, scientific journals that can be used by lecturers in proposing ranks and functional positions are electronic journals or have an online version published (Ministry of Research and Technology of the Republic of Indonesia, 2015). 
In addition, an important requirement as a national scientific journal that can be assessed is that published articles come from two or more institutions with editors or peer-reviewed from two institutions (Ministry of Research and Technology of the Republic of Indonesia, 2015). Many national journals that have been published have not met these requirements. The problem that is often faced by journal managers is getting an editor or peer-review that is relevant to the field of science that is not from the journal management institution. Such journals are included in the category of local journals which are not suitable for proposals for the rank and functional positions of lecturers.

Some lecturers are often fooled into publishing their journals in journals that are considered national journals, even though in fact they have not met the required criteria so that they are categorized as local journals. However, with the existence of electronic journals, lecturers can verify journals that can be searched by browsing the website so that it can be seen whether these journals qualify as national journals.

The development of web technology currently allows many publication activities to be packaged in an integrated manner in a portal (web page) in the form of communication, discussion, document submission, peer-review, feedback, and publication (Spicer, 2003). Therefore, electronic journals make it easy for each researcher / lecturer in the process of finding journal information that is in accordance with their field of study and makes it easier to send article files to be published.

To be able to publish research results in scientific journals generally requires quite a long time and a lot of money. One of the efforts to avoid this problem is to publish it in its own agency in collaboration with several institutions so that it is hoped that it will reduce costs and waiting time for publishing articles.

Medistra Lubuk Pakam Health Institute is a Health Education Institution that has good information and communication technology facilities and good human resources. Both of these aspects, it is deemed appropriate for the institution to require all its lecturers to have scientific publications that meet the requirements of national journals, namely journals managed by institutions, authors from two institutions, and managed by editors or peer reviews from two institutions (Ministry of Research and Technology of the Republic of Indonesia, 2015).

However, the human resources (lecturers) are not yet capable of publishing their work in online publications. When viewed from the small number of lecturer publications, it shows that the knowledge of lecturers in both institutions is still lacking. In general, the experience of lecturers in writing scientific papers is still limited to writing theses and theses, while writing scientific papers in the form of journals or books does not yet exist. This shows that the skills and techniques of writing scientific papers are still lacking so that lecturers still need to get assistance at an early stage.

Information obtained through interviews with lecturers who have published scientific papers shows that so far they still rely on publishing their scientific journals in hardcopy form. They do not know that for a long time, many journal managers have published scientific papers in online form and published on electronic journal website pages known as the open journal system (OJS).

Open Journal Systems (OJS) is designed to facilitate the development of an open access system for peer-reviewed publications, providing a technical infrastructure not only for the online presentation of journal articles, but also the entire editorial management workflow, which includes: article submission, peer-review activities, and indexing (OJS, 2013a; OJS, 2013b). Therefore, it will be very helpful in expediting and shortening the process of 
scientific publication. The convenience provided is expected to motivate writers to publish scientific papers in website-based electronic journals. The review process will be run more efficiently without going through an intermediary for the journal manager.

Based on observations of a number of lecturers at the Lubuk Pakam Medistra Health Institute, information was obtained:

1.

2.

Lack of knowledge of lecturers in writing scientific journals,

3. Lack of lecturer knowledge in submitting articles online, electronic journals.

There has never been an institutional effort to assist lecturers in publishing

For this reason, it is necessary to hold training and mentoring activity for lecturers in helping to publish scientific papers at the two institutes. There are two achievements in this training, namely that lecturers have the skills to write scientific articles as well as knowledge on how to check the originality of their own scientific work (using the plagiarism checker application) where less than $20 \%$ of plagiarism is detected in the original category.

\section{METHOD}

This activity was carried out at the Deli Husada Health Institute, Deli Tua. The target audiences in this activity are permanent foundation lecturers who have served at least one year and have sufficient abilities in the field of ICT. As for those who participated in the scientific paper writing assistance activities were all lecturers in the institution, totaling 28 lecturers who were held for two months, namely from May and June 2018.

This assistance is an activity that aims to produce something or activity. In this activity, the mentoring in question is aimed at producing and improving the skills of lecturers in writing scientific articles that are worthy of being published with a high level of originality. Therefore, the data analysis used is descriptive qualitative analysis with a minimum success achievement of $60 \%$.

\section{RESULTS AND DISCUSSION}

The training that has been carried out shows that there is an increase in the interest of participants to take part in similar training activities as shown in the following table:

Table 1. Training Results

\begin{tabular}{lcccc}
\hline & \multicolumn{2}{c}{$\begin{array}{c}\text { Number of Participants at } \\
\text { Stage }\end{array}$} & Total Number of Participants \\
\cline { 2 - 5 } & I & II & N & $\%$ \\
\hline $\begin{array}{l}\text { Scientific Article } \\
\text { Writing }\end{array}$ & $12 / 14$ & $14 / 14$ & $26 / 28$ & 92,86 \\
$\begin{array}{l}\text { Article Originality } \\
\text { Check }\end{array}$ & $8 / 14$ & $10 / 14$ & $18 / 28$ & 64,29 \\
\hline
\end{tabular}

This means that the training activities in stage I only produced 8 out of $14(57.14 \%)$ articles belonging to original participants and suitable for publication in national journals and an increase of 10 out of $14(71.43 \%)$ articles again after phase II activities, so that The total average of articles that are fit for publication and meet originality is $64.29 \%$. This activity shows satisfactory success when compared with the expected achievement plan, namely $60 \%$ of the total number of activity participants. Some of the reasons for the success of this 
activity were the high interest and motivation of activity participants to participate because they felt that the training provided would be useful for them (Nawangwulan, 2018).

Motivation, direction and supervision provided by the leadership (Widjaja, 1985) will determine the success of an organizational activity, in this case an electronic journal writing assistance activity. The participation of the Foundation and the leaders of the two agencies also contributed so that activities could run well and smoothly. The support provided is in the form of motivation and direction to take part in writing electronic scientific journals as well as supervision by the leadership to be able to publish journal articles at least one article a year are part of the success of this mentoring activity as stated by Fazrien (2014) that the role of the leadership will be very influential in achieving employee performance.

In addition, writing guidance will be more effective and efficient if it is done online (Surjono, 2013). This is because peer reviews can monitor incoming articles for inspection after meeting the initial requirements, namely the suitability of the article title with the theme or focus of the field and the suitability of the specified article template.

However, there are still many obstacles faced by the lecturers themselves, such as the lack of research activities carried out by the lecturers, as shown in this activity, that only $64.29 \%$ of the articles were declared in the original category. This is in line with Zhou's (2013) statement, that publication productivity can be influenced by many factors such as database entry, policy evaluation, research and development investment and the number of researchers.

\section{CONCLUSION}

Publication is one of the best way to communicate results of research. The writing lecturers' scientific papers can significantly improve the ability of lecturers to produce scientific papers that can be published, where more than $60 \%$ of participants have scientific articles that are worthy of publication.

\section{REFERENCES}

Fazrien, A., Sumartono, \& Domai, T. 2014. The Role of Leaders in Achieving Employee Performance (Study at the Regional Civil Service Agency of Malang City). Journal of Public Administration, Vol. 2 (4), p. 603-607.

Ministry of Education and Culture. 2014. Operational Guidelines for Assessing Lecturers' Academic Rank Promotion / Position Credit. Jakarta: Directorate General of Higher Education.

Ministry of Research and Technology of the Republic of Indonesia. 2015. Circular Letter of the Directorate General of Science and Technology and Higher Education Resources No. 1864 / E4 / 2015 concerning Circular of Lecturer Credit Score Assessment. Jakarta, Directorate General of Resources, Science, Technology and Higher Education.

Nasution, M.K.M. 2016. Research Phenomena. Daily Analisa, Opinion: Published on Tuesday, May 24 2016. DOI: 10.13140 / RG.2.2.20287.41129

Nawangwulan, Sri. 2018. Analysis of Training Needs and Human Resource Development. Journal of Hospital Foundation Health Management. Dr. Soetomo, Vol. 4 (1), p. 24-29.

OJS. 2013a. "Subscriptions". Open Journal Systems Help. Retrieved 25 February 2013.

OJS. 2013b. Open Journal Systems ". Public Knowledge Project. Retrieved 25 February 2013. 
Spicer, D. 2003. Where the Rubber Meets The Road: An On-Campus Perspective of a CIO. In M.S. Pittinsky (Ed), The Wired Tower. Upper Saddle River, N.J .: Financial Times Prentice Hall.

Surjono, H.D., Sumardiningsih, S., Respti, D., \& Widiatmono, R. 2013. The effectiveness of online writing guidance through the KTI website. Journal of Education, Vol 43 (2), p. 116-123.

Widjaja A.W. 1985. Leadership Pattern and Pancasila Leadership. Bandung: Armico.

Zhou P. 2013. The growth momentum of China in producing international scientific publications seems to have slowed down. Journal of Information Processing and Management. 49: 1049-1051. 